\title{
LEKSIKON PERTANIAN PADA MASYARAKAT DAYAK MAANYAN \\ (Agriculture Lexicons in Dayak Maanyan Community)
}

\author{
Dwiani Septiana \\ Balai Bahasa Kalimantan Tengah \\ Jalan Tingang Km. 3,5 Palangka Raya, Kalimantan Tengah \\ Posel: dwianiseptiana22@gmail.com
}

(Naskah Diterima Tanggal 24 April—Direvisi Tanggal 15 Desember—Disetujui Tanggal 28 Desember)

\begin{abstract}
The purpose of this research was to describe and documented agriculture lexicons in the Maanyan community and also explain those lexical meaning. This research uses semantic theory. The data for this research were collected by observation and interview with the Maanyan community in Paku Beto village, East Barito regency. The result indicates that there are at least 13 lexicons that describe the stages of farming, 25 lexicons in agriculture's tools and equipment and there is at least 24 lexicon concerning the condition of rice and activities related to rice in Maanyan community.
\end{abstract}

Keywords: lexicon, agriculture, Dayak Maanyan

\begin{abstract}
Abstrak
Penelitian ini bertujuan untuk mendeskripsikan dan men- dokumentasikan leksikon pertanian pada masyarakat Maanyan dan menjelaskan makna leksikal dalam leksikon pertanian tradisional pada masyarakat Maanyan. Penelitian ini menggunakan konsep dasar teori semantik. Pengumpulan data penelitian dilakukan dengan observasi dan wawancara pada masyarakat Maanyan di desa Paku Beto, kecamatan Paku, kabupaten Barito Timur. Hasil penelitian menunjukan bahwa terdapat sedikitnya 13 leksikon yang berkaitan dengan tahapan yang dilakukan untuk menghasilkan padi, mulai dari mencari lahan sampai masa panen, 25 leksion yang berkaitan dengan peralatan atau perkakas pertanian dalam masyarakat maanyan dan dalam deskripsi mengenai kondisi padi dan kegiatan-kegitan yang dilakukan berkenaan dengan padi terdapat sedikitnya 24 leksikon.
\end{abstract}

Kata Kunci: leksikon, pertanian, Dayak Maanyan

\section{PENDAHULUAN}

Leksikon atau kosakata pada sebuah bahasa memberikan sebuah katalog atau daftar tentang segala sesuatu yang dianggap penting dalam sebuah masyarakat (SavilleTroike, 2003: 28). Satu hal yang penting dalam masyarakat Maanyan adalah pertanian. Sejak jaman dahulu bahkan sampai saat ini (sebagian) masyarakat Maanyan menggantungkan hidupnya dari hasil-hasil pertanian. Untuk mencukupi kebutuhan hidup sehari-hari mereka berladang, menanam padi, menyadap karet, berburu binatang, mencari ikan dan lain sebagainya. Kegiatan ini berlangsung dari pagi sampai menjelang sore. Kebanyakan hidup mereka berada di ladang dan kebun karet. Hal ini tentu saja menjadikan masyarakat ini kaya akan leksikon-leksikon yang berkaitan dengan pertanian tradisonal. 
Namun tidak dapat dipungkiri pesatnya perkembangan ilmu pengetahuan dan teknologi serta sentuhan modernisasai yang mulai masuk sampai ke pedalaman Kalimantan banyak mengubah cara pandang dan pola hidup masyarakat Maanyan. Sebagian besar generasi mudanya sudah meninggalkan pekerjaan yang berkaitan dengan pertanian (berladang dan menyadap karet) beralih menjadi pekerja-pekerja pada pemeritahan, perusahaan batu-bara, atau perusahaan swasta lainnya yang mulai masuk ke wilayah pemukiman masyarakat Maanyan. Selain itu semakin berkurangnya lahan-lahan pertanian untuk berladang dan berkebun karet karena dijual pada perusahaan batu-bara ataupun perusahaan sawit yang lebih menjanjikan secara finansial.

Selain permasalahan yang berkaitan dengan pergeseran cara pandang dan pola hidup masyarakatat Maanyan, masuknya teknologi dalam bidang pertanian juga menyebabkan banyak terjadi perubahan dalam pola-pola pertanian tradisional masyarakat Maanyan. Banyak alat-alat pertanian modern yang digunakan menggantikan peralatan pertanian tradisional, pupuk buatan pabrik dan obatobatan pembasmi hama yang digunakan menggantikan pupuk tradisional dan polapola pembasmian hama yang dilakukan secara tradisional. Teknologi ini tentunya lebih memudahkan masyarakat dalam bertani. Namun kondisi ini akan memaksa hilangnya pengetahuan yang berkaitan dengan pertanian tradisional termasuk di dalamanya leksikon-leksikon pertanian tradisional dalam masyarakat Maanyan.

Berkenaan dengan hal-hal yang telah diuraikan di atas maka penulis merasa penting untuk melakukan pendokumentasian terhadap leksikon pertanian tradisonal yang ada di kalangan masyarakat Maanyan dan mengklasifikasi serta mendeskripsikan leksikon-leksikon tersebut. Permasalahan yang akan dikaji dalam penelitian ini adalah bagaimana bentuk leksikon pertanian yang digunakan oleh masyarakat Maanyan dan bagaimana makna leksikal dalam leksikon pertanian tradisional pada masyarakat Maanyan? Tujuan yang ingin dicapai dalam penelitian ini adalah mendeskripsikan dan mendokumentasikan leksikon pertanian pada masyarakat Maanyan dan menjelaskan makna leksikal dalam leksikon pertanian tradisional pada masyarakat Maanyan

Penelitian ini bermanfaat karena berdasarkan leksikon pertanian yang diperoleh banyak hal mengenai leksikon pertanian, budaya, kehidupan tradisional, hubungan manusia dengan alam dan dengan sesamanya dalam masyarakat Maanyan dapat dipahami. Di samping itu penelitian ini diharapkan juga bermanfaat sebagai salah satu dokumentasi leksikon pertanian yang mampu menjadi acuan dalam penggalian nilai-nilai budaya lokal, khususnya budaya Maanyan, oleh pemerintah, akademisi, maupun masyarakat umum secara keseluruhan.

Beberapa hasil penelitian yang berhubungan dengan penelitian ini antara lain penelitian yang dilakukan oleh (Nurhayati, 2010) dengan judul Pengaruh Teknologi Mesin Terhadap Perubahan Kosakata di Bidang Pertanian: Sebuah Kajian atas Masyarakat Petani di Kabupaten Blora. Nurhayati (2010) dalam penelitian ini menyebutkan bahwa para petani di daerah kabupaten Blora sudah mulai meninggalkan penggunaan beberapa kosakata yang biasanya digunakan dalam pertanian tradisional dikarenakan pengguaan teknologi modern dalam pertanian. Menurutnya teknologi modern tidak hanya mengubah penggunaan kosakata dalam praktek pertanian tetapi juga mengubah cara-cara pertanian tradisonal termasuk di dalamnya upacara-upacara tradisonal berkaitan dengan pertanian juga sudah mulai menghilang dari masyarakat di daerah tersebut. Darpan, dkk. 
(2013) melalui penelitian di daerah Sunda mendokumentasikan sistem pertanian tradisional Sunda dalam sebuah buku Kompedium Istilah Sistem Pertanian Tradisional Sunda. Menurut mereka sangat banyak tata cara bertani secara tradisional yang kini menghilang dari masyarakat. Beberapa hal yang memengaruhinya antara lain adalah penerapan cara bertani modern yang didukung oleh teknologi pertanian yang lebih canggih sehingga memudahkan pekerjaaan para petani dan mampu meningkatkan produksi pertanian. Selain itu menurut mereka penyempitan lahan pertanian akibat industrialisasi juga menjadi faktor yang mempengaruhi hilangnya sistem-sistem pertanian tradisional dari masyarakat Sunda.

Berdasarkan beberapa penelitian sebelumnya maka dapat disimpulkan bahwa penelitian ini memiliki beberapa persamaan dan perbedaan. Persamaannya terletak pada objek penelitian yang sama yaitu pertanian tradisional dalam sebuah masyarakat. Adapun perbedaan penelitian ini dengan penelitian sebelumnya terletak pada permasalahan yang akan dikaji dan metode yang digunakan dalam penelitian. Selain itu menurut pengamatan peneliti belum ada penelitian sebelumnya yang membahas tentang pertanian tradisional dalam masyarakat Maanyan dalam disiplin ilmu linguistik.

Setiap penelitian memerlukan teori yang sesuai dengan masalah yang diteliti. Teori digunakan sebagai dasar, tuntunan, dan arah kajian yang berkaitan dengan penelitian. Penelitian ini menggunakan konsep dasar teori semantik. Adelaar, (1985: 132) dalam penelitiannya tentang Proto Bahasa Melayu menyebutkan bahwa leksikon berkaitan dan dapat didefinisikan dengan baik dalam bidang semantik. Semantik merupakan cabang linguistik yang mempelajari tentang makna bahasa (Crystal, 2008: 428). Kridalaksana (2008: 216) mendefinisikan semantik sebagai bagian dari struktur bahasa yang berhubungan dengan makna ungkapan dan juga dengan struktur makna suatu wicara. Menurut Chaer (2007: 289) makna bahasa dapat bermacam-macam karena bahasa digunakan untuk berbagai kegiatan dan keperluan dalam kehidupan bermasyarakat. Salah satu makna yang dimaksud adalah makna leksikal.

Makna leksikal adalah makna yang dimiliki atau ada pada sebuah kata meski tanpa konteks apa pun (Chaer, 2007: 289). Menurut Pateda (2001: 119) makna leksikal yaitu makna kata ketika kata itu berdiri sendiri, dalam bentuk laksem atau berimbuhan yang maknanya kurang lebih tetap. Jadi makna leksikal adalah makna yang dimiliki oleh sebuah kata, baik ketika kata tersebut berdiri sendiri ataupun dalam bentuk kata berimbuhan.

Istilah leksikon identik dengan kosa kata (Crystal, 2008: 278). Menurut Verhaar (2010: 13) istilah leksikon dalam ilmu linguistik berarti perbendaharaan kata. Menurutnya setiap bahasa mempunyai perbendaharaan kata yang cukup besar, dan setiap kata mempunya arti atau makna tersendiri. Chaer (2007: 5) memadankan leksikon dengan kosakata, perbendaharaan kata dan vokabuler. Menurutnya istilah leksikon berasal dari bahasa yunani kuno lexicon yang berarti kata, ucapan, atau cara berbicara. Kridalaksana (2008: 142) mendefinisikan leksikon sebagai komponen bahasa yang memuat semua informasi tentang makna dan pemakaian kata dalam bahasa. Sementara itu Langacker (2014: 27) memandang leksikon dari sisi yang berbeda, menurutnya leksikon merupakan daftar berbagai macam hal yang dipelajari, dan proses pemerolehanya melalui interaksi dengan lingkungan sosial budayanya karena itu leksikon berhubungan erat dengan budaya masyarakat pendukungnya. Serupa dengan itu Sapir (2001: 14) juga menyebut bahwa kosakata dari sebuah bahasa 
mereflesikan lingkungan fisik dan sosial penuturnya. Jadi leksikon merupakan kata atau kosa kata dalam sebuah bahasa yang memiliki makna sendiri dan memiliki hubungan dengan budaya masyarakat.

\section{METODE PENELITIAN}

Penelitian ini menggunakan metode penelitian etnografi. Menurut Copland dan Creese (2015: 13-14) etnografi memungkinkan manusia untuk melihat bagaimana bahasa berhubungan dengan kondisi nyata kehidupan manusia, untuk menemukan bagaimana dan mengapa bahasa merupakan hal yang penting dalam kehidupan manusia serta melihat bagaimana prosesnya dari waktu ke waktu, etrnografi juga dapat menceritakan sebuah pengalaman yang menghasilkan sebuah penjelasan kenapa manusia melakukan dan memikirkan hal yang mereka lakukan. Saville-Troike (2003: 1) mengatakan bahwa etnografi adalah penelitian lapangan yang terutama berkaitan dengan deskripsi dan analisis budaya dan kode-kode linguistik. Dalam melaksanakan etnografi peneliti harus melakukan penelitian lapangan yang berupa observasi, mengajukan pertanyaan, partisipasi dalam aktivitas kelompok serta mengecek validitas persepsi orang dengan intuisi penutur asli (Saville-Troike, 2003: 3). Lokasi penelitan adalah desa Paku Beto, kecamatan Paku, kabupaten Barito Timur.

Pengumpulan data penelitian dilakukan dengan observasi dan wawancara. Observasi dilakukan untuk mengamati apa yang dipakai dan dikerjakan orang serta mendengarkan apa yang diucapkan oleh masyarakat Maanyan dalam bertani. Untuk melengkapi data penelitian, peneliti juga tinggal dan terlibat dalam kehidupan seharihari masyarakat Maanyan di desa Paku Beto. Wawancara juga dilakukan dalam pengumpulan data utama. Stainback dalam Sugiyono (2009: 232) mengemukakan bahwa melalui wawancara peneliti akan mengetahui hal-hal yang lebih mendalam tentang partisipan dalam menginterpretasikan situasi dan fenomena yang terjadi, hal ini tidak bisa ditemukan melalui observasi saja. Penelitian ini menggunakan teknik wawancara terstruktur. Teknik ini digunakan kerana peneliti telah mengatahui dengan pasti tentang informasi apa saja yang ingin diperoleh dari narasumber. Oleh karena itu dalam melakukan wawancara peneliti telah menyiapkan instrumen penelitian berupa daftar pertanyaan-pertanyaan tertulis yang beikaitan dengan leksikon pertanian dalam masyarakat Maanyan.

Langkah-langkah analisis data dalam penelitian ini adalah: (1) Data yang diperoleh dipilih dan difokuskan pada halhal yang penting dalam pertanian masyarakat Maanyan; mengklasifikasikan makna lesikon pertanian tradisional pada masyarakat Maanyan yang berkaitan dengan perkakas petani, alat-alat pertanian, kondisi padi, istilah-istilah yang digunakan dalam berladang serta pekerjaan yang dilakukan sebelum dan sesudah berladang; (3) menjelaskan makna yang ada pada leksikon yang berkaitan dengan pertanian tradisional pada masyarakat maanyan; (4) tahap terakhir dari analisis data adalah penyimpulan. Hasil analisis disimpulkan sehingga akan menghasilkan deskripsi tentang leksikon pertanian dalam masyarakat Maanyan.

\section{PEMBAHASAN}

\section{Sistem Pertanian Tradisonal Masyarakat Maanyan}

Masyarakat Maanyan kuno mengenal sistem pertanian di ladang di daerah perbukitan bila musim penghujan dan di daerah rawa atau lahan berair bila musim kemarau datang. Menurut catatan Bae, dkk. (1995) masyarakat Maanyan kuno menentukan 
lokasi bertani dengan melihat keadaan musim yang ditentukan berdasarkan posisi bintang-bintang. Bila garis edar matahari berhimpit dengan garus edar Ursa Mayor maka musim yang akan dihadapi pada tahun tersebut adalah musim penghujan dan mereka akan membuka ladang di daerah perbukitan. Sebaliknya bila terdapat jarak antara garis edar matahari dan Ursa Mayor maka musim yang akan dihadapi pada tahun tersebut adalah musim kemarau dan mereka akan membuka ladang di daerah rawa atau lahan berair. Biasanya musim kemarau panjang, menurut perhitungan akan datang setiap lima tahun sekali.

Sistem pertanian tradisional dengan melihat posisi bintang ini sudah sepenuhnya ditinggalkan oleh masyarakat Maanyan dengan masuknya sistem perhitungan tahun berdasarkan kalender dengan perhitungan hari yang tepat. Saat ini musim menanam padi di lakukan antara bulan Oktober dan November saat hujan pertama setelah musim kemarau berlalu dan masa panen akan berlangsung antara bulan April sampai Mei.

Berikut beberapa tahap dalam pertanian tradisional masyarakat Maanyan yang dilakukan di ladang di daerah perbukitan atau di darat yang dikenal dengan istilah sawah entu 'sawah darat' atau sawah tadah hujan.

1. Suwuk jumpun, kata suwuk secara harfiah akan berarti 'menjenguk atau melihat' dan jumpun 'hutan', jadi suwuk jumpun mengandung makna melihat atau mencari tempat atau lokasi untuk menanam padi. Masa berladang akan dimulai dengan menentukan lokasi yang biasanya berlangsung di antara bulan Mei, Juni atau Juli pada penanggalan kalender modern, setelah berakhir masa panen sebelumnya.

2. Ngulah siri, kata ngulah berarti 'membuat' dan siri berarti 'ciri', ngulah siri mengandung makna membuat ciri atau tanda di mana lokasi berladang akan dilakukan. Setelah suwuk jumpun ditemukan lokasi tempat berladang maka akan dibuat ciri atau tanda berupa batang kayu yang agak besar sebanyak 5 buah, disusun menjadi tempat duduk atau beristirahat, kegiatan ini disebut dengan ngulah wila bata.

3. Tamaruh, berasal dari kata taruh yang berarti 'parang'. Tamaruh mengandung makna membersihakan lahan semaksemak dan pepohonan kecil dengan menggunakan taruh. Kegiatan ini biasanya berlangsung di sekitar bulan Juli.

4. Neweng berarti 'menebang'. Setelah selesai membersihkan semak-semak dan pepohonan kecil di lokasi berladang maka tahapan selanjutnya disebut dengan

neweng yaitu menebang pohon-pohon besar dengan menggunakan wadiung alat seperti kapak yang biasanya digunakan untuk menebang pohonpohon besar.

5. Hanradah atau iradah berarti memotong dahan-dahan kayu dari pohon-pohon besar yang telah ditebang.

6. Nelai jawe, kata nelai berarti 'jemur' dan jawe 'dahan' atau 'ranting'. nelai jawe merupakan kegiatan menjemur atau mengeringkan hasil tebangan pohon dan semak-semak agar mudah dimakan api. Masa nelai jawe ini bisa berlangsung sampai 3 minggu antara bulan Juli atau Agustus

7. Nutung jawe berarti membakar sisa-sisa tebasan dan tebangan di ladang. Setelah masa nelai jawe berkahir dan dahan, ranting serta semak-semak hasil tebangan dirasa sudah kering maka tahapan selanjutnya adalah pembakaran lahan atau nutung jawe. Kegiatan ini bertujuan untuk membersihkan lahan dan biasanya dilakukan di bulan Agustus atau September. Sebelum proses pembakaran lahan dilakukan 
terlebih dahulu dibuat jalur pembatas seperti parit kecil untuk mencegah api menyebar ke lahan lainnya dan kebakaran hutan, kegiatan ini dinamakan ranrang.

8. Mupuh ume berarti 'menandai ladang'. Setelah lahan tempat berladang bersih dibakar, selanjutnya adalah menandai ladang dengan menanam sakur 'kencur' sarai 'serai' dan rirung sejenis tanaman dengan daun lebar berwarna merah. Kegiatan mupuh ume ini dimaksudkan untuk menandai ladang agar jangan diakui atau diambil oleh kariau sejenis mahluk halus di hutan biasanya meyerupai manusia.

9. Ipandruk berasal dari kata pandruk yang berarti unggunan atau susuan kayu yang dibakar. Ipandruk berarti membuat unggunan kayu bakar. Kegiatan ini dilakukan setelah selesai masa pembakaran lahan dan masih tersisa batang kayu-kayu besar yang tidak habis dimakan api. Sisa-sisa bakaran tersebut dipotong dan dibuat api unggun yang disebut dengan mate pandruk. Mate pandruk ini akan dinyalakan setiap kali datang ke ladang, untuk mengasapi ladang dan sebagai tanda ada kehidupan di tempat tersebut.

10. Миаи berarti menanam padi. Menanam padi dimulai pada bulan Oktober atau November. Bae dkk (1995) mencatat bahwa musim menanam padi pada masyarakat Maanyan kuno dimulai bila di kaki langit terdapat empat bintang di atas dua dari tiga bintang yang paling terang pada Big Dipper dalam konstelasi Ursa Mayor (dalam istilah Maanyan bintang ini dinamakan Awahat) biasanya dalam bulan Oktober. Hudson (1972) dalam penelitiannya pada masyarakat Maanyan di wilayah Paju Epat juga mencatat hal yang sama yaitu musim menanam padi dimulai pada bulan Oktober setelah hujan ringan pertama. Masa menanam padi sudah harus berakhir bila bintang Awahat telah mendekati kaki langit, biasanya terlihat di bulan Desember dan masa panen akan dimulai bila posisi bintang Orion tepai berada di atas ubun-ubun pada pukul 19.00-20.00 (Bae dkk, 1995)

Dahulu saat sebagain besar masyarakat Maanyan masih menganut kepercayaan Kaharingan proses muau diawali dengan proses meminyaki benih padi atau ngilau wini yaitu kegiatan yang dilakukan untuk memohon kesuburan bagi benih padi. Kegiatan muau biasanya dilakukan bersama-sama dengan orang-orang di kampung dengan menggunakan sejenis tongkat kayu panjang dan runcing untuk melobangi tanah tempat meletakan benih padi. Tongkat kayu tersebut dinamakan ehek dan dipegang oleh para lelaki di barisan depan dan wanita di barisan belakang, membawa dan meletakan benih padi ke dalam lobang yang telah dibuat, begitu seterusnya sampai seluruh ladang ditanami benih. Untuk mengatur proses selama тиаи ini ada seorang pemimpin yang dituakan dan berpengalaman biasanya disebut makas (Suwito, 2009).

11. Nyawah berarti membersihkan sawah. Kegiatan ini merupakan kegiatan pemeliharaan ladang. Sesekali si empunya ladang akan datang untuk membersihkan rumput di sela-sela tanaman padi. Nyawah dilakukan dengan menggunakan parang kecil yang disebut $u d u k$

12. Ngandrei parei berarti menunggu padi, masa ini akan berlangsung selama 3-5 bulan atau 25 minggu tergantung jenis padi yang ditanam. Selama masa menunggu tidak banyak kegiatan yang dilakukan berkaitan dengan ladang padi selain nyawah. Biasanya selama masa tunggu ini masyarakat akan menyadap karet atau disebut dengan mamantat 
atau berburu dan menangkap ikan sebagai lauk.

13. Masi berarti panen, sama seperti saat menanam, saat panen pun dikerjakan bersama-sama dengan orang-orang di kampung. Masa panen biasanya berlangsung antara akhir bulan April sampai Juli. Dalam masyarakat Maanyan dikenal istilah panganrau yaitu bekerja besama-sama atau saling membantu di dalang untuk menanam padi atau panen. Kegiatan ini dilakukan sesara bergantian atau berbalasan.

\section{Deskripsi Leksikon Pertanian Maanyan}

Sebelumnya telah dijelaskan tentang sistem pertanian tradisional dan kegiatan yang berkaitan dengan pertanian dalam masyarakat Maanyan. Berikut ini akan dideskripsikan leksikon-leksikon yang berkaitan dengan pertanian masyarakat Maanyan. Deskripsi tersebut akan dibagi menjadi dua bagian yaitu perkakas atau peralatan yang digunakan dan kondisi padi serta kegiatan-kegiatan yang dilakukan berkenaan dengan padi sampai menjadi beras.

\section{Perkakas Pertanian}

Berikut deskripsi leksikon pertanian yang berkaitan dengan perkakas atau peralatan yang digunakan oleh para petani dalam masyarakat Maanyan

Tabel 1. Deskripsi Perkakas Pertanian

\begin{tabular}{|c|c|}
\hline Leksikon & Makna \\
\hline Alu & Alat untuk menumbuk padi di lesung \\
\hline Bagah & $\begin{array}{l}\text { Sejenis wadah atau tempat yang terbuat dari anyaman } \\
\text { rotan dengan mulut berbentuk lingkaran dan bagian } \\
\text { bawahnya berbentuk persegi, memiliki ukuran yang } \\
\text { besar dan dapat memuat } 5 \text { sampai } 6 \text { belek beras (1 } \\
\text { belek setara dengan takaran } 10 \mathrm{~kg} \text { ). Bagah dibawa } \\
\text { dengan menggendong di punggung seperti tas ransel }\end{array}$ \\
\hline Bajut & $\begin{array}{l}\text { Sejenis bakul atau wadah yang terbuat dari anyaman } \\
\text { rotan berbentuk persegi di bagian bawah dan mulut } \\
\text { yang lebih kecil. Biasanya digunakan sebagai tempat } \\
\text { meletakan benih/bibit padi }\end{array}$ \\
\hline Buntat & $\begin{array}{l}\text { Sejenis wadah atau tempat yang terbuat dari anyaman } \\
\text { rotan dengan mulut berbentuk lingkaran dan bagian } \\
\text { bawahnya berbentuk persegi, memiliki ukuran yang } \\
\text { lebih kecil dari bagah dan hanya dapat memuat } \\
\text { sekitar } 1 \text { belek beras atau padi. Biasanya dibawa oleh } \\
\text { para lelaki. }\end{array}$ \\
\hline Bungai & $\begin{array}{l}\text { Lingkaran bulat tempat kepala pada topi lebar yang } \\
\text { digunakan untuk bekerja di ladang }\end{array}$ \\
\hline Dahuru & Nyiru \\
\hline
\end{tabular}


Suar Bétang, Vol.13, No.2, Edisi Desember, 2018: 217-227

\begin{tabular}{|c|c|}
\hline Ehek & $\begin{array}{l}\text { Tongkat kayu dengan ujung runcing untuk membuat } \\
\text { lubang di tanah yg akan ditanami benih }\end{array}$ \\
\hline Kakurung & $\begin{array}{l}\text { Bunyi-bunyian yang terpasang pada ehek atau alat } \\
\text { menungal yang akan berbunyi bila digerakkan }\end{array}$ \\
\hline Gentu & Alau untuk memanen padi (ani-ani) \\
\hline Gantang & $\begin{array}{l}\text { Takaran untuk beras atau padi. } 1 \text { gantang }=10 \mathrm{~kg} \text {, atau } \\
4 \text { gantang }=1 \text { belek } / \text { kaleng }(1 \mathrm{kaleng}=10 \mathrm{~kg})\end{array}$ \\
\hline Gaben & $\begin{array}{l}\text { Takaran untuk beras atau padi. } 2,5 \text { gaben }= \\
\text { lbelek/kaleng }\end{array}$ \\
\hline Jukan & $\begin{array}{l}\text { Tempat membawa padi setelah panen. Berbentuk } \\
\text { seperti lanjung besar yang dibawa di punggung }\end{array}$ \\
\hline Lehung & Lesung tempat menumbuk padi \\
\hline Upak & $\begin{array}{l}\text { Tempat yang terbuat dari kulit kayu berbentuk silinder } \\
\text { besar dan digunakan sebagai wadah untuk menyimpan } \\
\text { padi }\end{array}$ \\
\hline $\begin{array}{l}\text { Panuk } \\
\text { pamaaman }\end{array}$ & $\begin{array}{l}\text { Bakul yang dibuat seindah mungkin tempat benih padi } \\
\text { yang akan dimasukan ke lubang tugal, biasanya } \\
\text { dipakai oleh para gadis }\end{array}$ \\
\hline Рапипи & $\begin{array}{l}\text { Bakul khusus tempat menyimpan padi yang baru } \\
\text { dipanen }\end{array}$ \\
\hline Puru & $\begin{array}{l}\text { Tempat menyimpan padi yang terbuat dari kulit kayu } \\
\text { berbentuk silinder besar }\end{array}$ \\
\hline Tapan & Alat untuk menampi beras atau padi \\
\hline Taruh & Parang \\
\hline Turi Barung & $\begin{array}{l}\text { Sejenis parang kecil dengan tangkai yang panjang dan } \\
\text { besar }\end{array}$ \\
\hline Ummut & $\begin{array}{l}\text { Orang-orangan di ladang yang digunakan untuk } \\
\text { menakut-nakuti hewan perusak tanaman padi }\end{array}$ \\
\hline Witang & Tali untuk menggerakan orang-orangan di ladang \\
\hline Tampatai & $\begin{array}{l}\text { Tempat meletakan lesung dan alu untuk menumbuk } \\
\text { padi }\end{array}$ \\
\hline Wirang & $\begin{array}{l}\text { Lumbung padi berbentuk persegi dengan dinding } \\
\text { terbuat dari kulit kayu }\end{array}$ \\
\hline Wadiung & $\begin{array}{l}\text { Alat seperti kapak yang biasanya digunakan untuk } \\
\text { menebang pohon-pohon besar. }\end{array}$ \\
\hline
\end{tabular}




\section{Kondisi Padi}

Tabel 2 berikut merupakan deskripsi kondisi padi dalam masyarakat Maanyan sejak pertama kali ditanam sampai jadi sesuatu yang dapat dimakan dan kegiatan-kegitan yang dilakukan berkenaan dengan padi sampai menjadi beras.

\section{Tabel 2. Kondisi Padi}

\begin{tabular}{|c|c|}
\hline Leksikon & Makna \\
\hline Wini & Benih padi \\
\hline Parei & Padi \\
\hline Parei gilai & Nama jenis padi gogo \\
\hline Parei Raden & Nama jenis padi yang ditanam di lahan berair \\
\hline Parei Haring & Padi yang tumbuh sendiri \\
\hline Jurang & $\begin{array}{l}\text { Sebutan untuk buah padi yang belum matang pada } \\
\text { saat panen pertama }\end{array}$ \\
\hline Weah & Beras \\
\hline Dite & Beras ketan \\
\hline Ata & Sisa bulir padi yang masih utuh setelah ditumbuk \\
\hline Bulut & Keadaan nasi yang masih basah dan belum matang \\
\hline Wurai & Butiran nasi yang berbutir-butir tidak pulen \\
\hline Karau & Nasi yang keras \\
\hline Hewang & $\begin{array}{l}\text { Keadaan dimana tanaman pokok (padi) pada sebuah } \\
\text { ladang kalah subur dengan tanaman-tanaman } \\
\text { pengganggu }\end{array}$ \\
\hline Hemmai & Padi yang roboh karena angin atau banjir \\
\hline Pareeang & Jemuran padi \\
\hline Lelaian & $\begin{array}{l}\text { Jemuran padi, biasanya dalam jumlah yang banyak } \\
\text { untuk kemudian disimpan. }\end{array}$ \\
\hline Werang/merang & Menghampar padi di atas tikar untuk dijemur. \\
\hline Papai & $\begin{array}{l}\text { Air (yang telah didoakan) yang dipercikan pada padi } \\
\text { yang hampir matang agar terhindar dari penyakit } \\
\text { yang dapat merusak bulir padi. }\end{array}$ \\
\hline Rabun & $\begin{array}{l}\text { Membakar daun-daunan tertentu saat padi sedang } \\
\text { berbuah untuk mencegah penyakit pada tanaman } \\
\text { padi. }\end{array}$ \\
\hline Rariwut & $\begin{array}{l}\text { Memisahkan antara padi yang berisi dengan yang } \\
\text { hampa dengan menggunakan angin. }\end{array}$ \\
\hline
\end{tabular}


Suar Bétang, Vol.13, No.2, Edisi Desember, 2018: 217-227

\begin{tabular}{ll}
\hline Mutu parei & Menumbuk padi \\
Mutu taweah & Menumbuk padi untuk mendapatkan beras \\
Reah & Menumbuk padi untuk kedua kalinya saat sudah \\
& banyak yang menjadi beras \\
Gedup, gagedup & Bunyi tumbukan padi pada lesung \\
\hline
\end{tabular}

\section{PENUTUP}

Berdasarkan deskripsi terhadap lesikon pertanian dalam masyarakat Maanyan dapat disimpulkan beberapa hal, yaitu dalam sistem pertanian tradisional masyarakat Maanyan yang dilakukan di ladang di daerah perbukitan atau di darat yang dikenal dengan istilah sawah entu 'sawah darat' atau 'sawah tadah hujan', terdapat 13 leksikon yang berkaitan dengan tahapan yang dilakukan untuk menghasilkan padi, mulai dari mencari lahan sampai masa panen.

Dalam deskripsi mengenai peralatan atau perkakas pertanian sedikitnya terdapat sedikitnya 25 leksion yang berkaitan dengan peralatan atau perkakas pertanian dalam masyarakat Maanyan. Dalam deskripsi mengenai kondisi padi sejak ditanam sampai jadi sesuatu yang dapat dimakan dan kegiatan-kegitan yang dilakukan berkenaan dengan padi sampai menjadi beras terdapat sedikitnya 24 leksikon

\section{DAFTAR PUSTAKA}

Adelaar, K. A. (1985). Proto-Malayaic. Alblasserdam: Offsetdrukkerij Kanters B.V.

Bae, S. U., \& dkk. (1995). Sejarah Suku Dayak Maanyan, Banjar dan Merina di Madagaskar.

Chaer, A. (2007). Leksikologi dan Leksikografi Indonesia. Jakarta: Rineka Cipta.

Copland, F., \& Creese, A. (2015). Linguistic Ethnography. London: Sage Publications.

Crystal, D. (2008). A Dictionary of Linguistics and Phonetics (6th ed.). Oxford: Blackwell Publishing.

Darpan. (2013). Kompendium Istilah Sistem Pertanian Tradisional Sunda. Bandung: Pustaka Jaya.

Hudson, A. B. (1972). Padju Epat: The Maanyan of Indonesian Borneo. New York: Rinehart and Winston, Inc.

Kridalaksana, H. (2008). Kamus Linguistik Edisi Keempat. Jakarta: Gramedia Pustaka Utama.

Langacker, R. W. (2014). Culture and Cognition, Lexicon and Grammar. In M. Yamaguchi, D. Tay, \& B. Blount (Eds.), Approaches to Language, Culture, and Cognition The Intersection of Cognitive Linguistics and Linguistic Anthropology (pp. 27-49). New York: Palgrave Macmillan.

Nurhayati, N. (2010). Pengaruh Teknologi

Mesin Terhadap Perubahan

Penggunaan Kosa Kata Bidang 
Petanian (Sebuah Kajian atas

Masyarakat Petani di Kabupaten Blora).

PAROLE: Journal of Linguistics and

Education, 1(1), 51-71. Retrieved from

http://ejournal.undip.ac.id/index.php/pa role/article/view/810/698

Pateda, M. (2001). Semantik Leksikal.

Jakarta: Rineka Cipta.

Sapir, E. (2001). Language and

Environment. In A. Fill \& P.

Mühlhäusler (Eds.), The Ecolinguistics

Reader: Language, Ecology and

Environment (pp. 13-23). London and

New York: Continuum.

Saville-Troike, M. (2003). The Ethnography of Communication: An Introduction

(3rd Ed.). Malden; Oxford; Melbourne: Blackwell Publishing Ltd.

Sugiyono. (2009). Metode Penelitian

Kuantitatif, Kualitatif dan $R \& D$.

Bandung: Alfabeta.

Suwito, D. (2009). Menanam Padi Secara

Gotong Royong (Mu'au).

Verhaar, J. W. M. (2010). Asas-asas

Linguistik Umum. Yogyakarya: Gadjah

Mada University Press. 